Revue Française de Civilisation Britannique

\title{
Martine SPENSKY (dir.), Citoyenneté(s) : Perspectives internationales
}

Clermont : Presses universitaires Blaise Pascal, 2003

\section{François Poirier}

\section{(2) OpenEdition \\ Journals}

\section{Édition électronique}

URL : http://journals.openedition.org/rfcb/3482

DOI : $10.4000 /$ rfcb.3482

ISSN : 2429-4373

\section{Éditeur}

CRECIB - Centre de recherche et d'études en civilisation britannique

\section{Édition imprimée}

Date de publication : 1 avril 2005

ISBN : 2-911580-20-6

ISSN : 0248-9015

Référence électronique

François Poirier, «Martine SPENSKY (dir.), Citoyenneté(s): Perspectives internationales », Revue

Française de Civilisation Britannique [En ligne], XIII-2 | 2005, mis en ligne le 01 avril 2005, consulté le 25 septembre 2020. URL : http://journals.openedition.org/rfcb/3482 ; DOI : https://doi.org/10.4000/rfcb. 3482

Ce document a été généré automatiquement le 25 septembre 2020.

Revue française de civilisation britannique est mis à disposition selon les termes de la licence Creative Commons Attribution - Pas d'Utilisation Commerciale - Pas de Modification 4.0 International. 


\title{
Martine SPENSKY (dir.), Citoyenneté(s) : Perspectives internationales
}

\author{
Clermont : Presses universitaires Blaise Pascal, 2003
}

\section{François Poirier}

\section{RÉFÉRENCE}

Martine SPENSKY (dir.), Citoyenneté(s) : Perspectives internationales, Clermont : Presses universitaires Blaise Pascal, 2003, 209 p. ISBN 2-84516-232-4

1 Le débat politique européen, projet de constitution oblige, regorge de références à la citoyenneté et parce que le même mot, ou sa traduction à la fois convenue et étymologiquement proche, est employé à peu près partout, il est facile de s'imaginer que chacun parle de la même chose. Agréable illusion des responsables politiques qui espèrent ainsi que les peuples parleront, par leur bouche, d'une seule voix. Cependant, s'il ne faut pas confondre différence et divergence, il n'est pas nécessaire de jouer les Cassandre pour s'attendre à une jolie discorde lorsqu'il s'agira d'appliquer les principes de la citoyenneté dans les diverses contrées de notre bonne Europe. Il suffit, pour s'en convaincre, de lire les analyses que propose l'ouvrage qu'a dirigé Martine Spensky à partir d'un colloque organisé à l'Université Clermont 2.

2 Ce livre propose, outre quatre contributions traitant spécifiquement des îles Britanniques et de l'Australie, des chapitres sur la Russie, l'Espagne et la Belgique. S'y ajoutent encore des pages transnationales qui examinent la notion de citoyenneté sous l'angle du genre, et l'introduction générale de Martine Spensky. L'ensemble permet d'observer les grands modèles de citoyenneté, à savoir le modèle français de l'individu citoyen et le modèle anglais de l'individu inséré dans une communauté, dans leur évolution historique, dans les interactions intervenues entre eux, dans les compromis passés. Car nulle part ces deux modèles ne se rencontrent à l'état pur et c'est sans 
doute un élément important, qu'on le juge positivement ou non, du débat européen que de faire évoluer ces deux conceptions matricielles vers des pratiques et un discours qui les rapprochent. Or on ne peut prendre la mesure de ces évolutions que si l'on se situe dans une perspective de comparaison internationale.

Le questionnement auquel sont soumises les réalités nationales retenues dans l'ouvrage trouve sa source dans la confrontation des grandes idées fondatrices de la notion de citoyenneté, de Locke à Toqueville ou de Marshall à Schnapper, comme le montre fort clairement l'introduction de Martine Spensky. Pour ce qui concerne plus particulièrement le monde anglophone, l'étude de Raphaële Espiet sur les conceptions thatchériennes de la citoyenneté donne à voir l'aporie libérale qui, en affirmant le primat de l'individu, finit par réduire l'espace civique à peu de choses. Deirdre Gilfedder étudie comment, à l'occasion du sacrifice citoyen des Anzac pour la métropole britannique, s'affirme l'identité distincte du citoyen australien, tandis qu'Anouk Guiné explore les raisons qui font que les lois réprimant l'excision restent lettre morte au Royaume-Uni, dans une tension bloquée entre le droit de la personne humaine et le droit à la différence culturelle - différence que l'on retrouve revendiquée dans le mouvement écossais de recherche d'une citoyenneté distincte au sein de l'ensemble britannique. Cette association citoyenneté et identité est également explorée au travers de l'exemple russe tandis que la place des femmes, outre la contribution transversale d'Alisa Del Ré, est vue sous l'angle britannique (Anouk Guiné), espagnol (Danielle Bussis-Genevoix) et belge (Bérengère Marques-Pereira).

4 En bref, un livre stimulant sur un débat qui promet de rester longtemps d'actualité.

\section{AUTEURS}

FRANÇOIS POIRIER

Université Paris 13 